\title{
INVOLVEMENT OF MICROBIAL MATS IN DELAYED DECAY: AN EXPERIMENTAL ESSAY ON FISH PRESERVATION
}

\author{
MIGUEL INIESTO, ${ }^{*}$ ANA I. LOPEZ-ARCHILLA, ${ }^{1}$ MARIAN FREGENAL-MARTÍNEZ, ${ }^{2}$ ANGELA D. BUSCALIONI,${ }^{3}$ \\ and M. CARMEN GUERRERO ${ }^{1}$ \\ ${ }^{1}$ Universidad Autónoma de Madrid, Department of Ecology,28049 Madrid, Spain, miguel.iniesto@uam.es, anabel.lopez@uam.es, carmen.guerrero@uam.es; ${ }^{2}$ Universidad \\ Complutense de Madrid, Department of Stratigraphy, 28040 Madrid, Spain.mariana@geo.ucm.es; ${ }^{3}$ Universidad Autónoma de Madrid, Department of Biology, 28049 \\ Madrid, Spain.angela.delgado@uam.es
}

\begin{abstract}
Microbial mats have been implicated in exceptional fossil preservation. Few analyses have addressed how these complex-multilayered biofilms promote fossil preservation. The sequence of changes during decay of neon tetra fish were tracked up to 27 months, and their decomposition in mats was compared against nonmat sediments (control fish). Statistically significant differences in quantitative variables (length, width, and thickness) are provided (ANOVA test, in all cases, $\mathrm{P}<0.001$ ). Changes in the qualitative features (body-head, fins, scale connection, and eye and body coloration) were phenetically analyzed resulting in two clusters and highlighting that notable differences in decay began at day 15. Mat fish show a delayed decomposition maintaining the external and internal body integrity, in which soft organs were preserved after 27 months as shown by Magnetic Resonance Imaging. We discuss how the organization, structure, and activity of this community are interrelated, favoring exceptional preservation. Microbial mats entomb the fish from the earliest stages, forming a Ca-rich coat over the carcass while embedding it in an anoxic condition. This quick entombment provides important protection against abiotic and/or biotic agents.
\end{abstract}

\section{INTRODUCTION}

Microbial mats are complex benthonic multilayered communities The community bears different physicochemical properties generated by light penetration and the activity of microorganisms along a vertical gradient (Cohen, 1989; Wierzchos et al., 1996). The multilayer mats grow continuously, with oxygenic photosynthetic (mainly filamentous cyanobacteria) and aerobic heterotrophic microorganisms in the oxic upper layer, overlying an anoxic deeper layer characterized by several anoxygenic photosynthetic bacteria (of the Chromatiaceae and Chlorobiaceae groups) and anaerobic microorganisms (such as fermenters or sulphate-reducing bacteria). The transition from the oxic to the anoxic zone and the flux and nutrient recycling among trophic levels occur within a few millimeters of the mat surface, giving these communities the character of a microecosystem in their own right.

During mat growth, organic remains, sedimentary particles, and bioinduced precipitates are trapped by the entangled structure of the community (Krumbein, 1979). In fact, microbial mats play a crucial role in the formation of microbially induced sedimentary structures (MISS) encompassing the regular deposition of sand, the accumulation of sediment, and the subsequent mat cover (Noffke, 2009). The frequent association of fossilized microbial mats with better-preserved fossils has been treated as a positive consequence for exceptional preservation, accumulation and ecological fidelity in Konservat Lagerstätten (Gall et al., 1985; Gall, 1990; Seilacher et al., 1985; Seilacher, 1990, 2009; Behrensmeyer, 2000; Briggs, 2003b; Buscalioni and Fregenal-Martínez, 2010). Mat properties that have been proposed to promote exceptional

\footnotetext{
* Corresponding author.
}

Published Online: January 2013

Copyright (C) 2013, SEPM (Society for Sedimentary Geology) fossil preservation include: (1) envelopment (growth of the mat over the body); (2) pseudomorphism (replication of the body surface by microbial growth); (3) protection (from scavengers and from water currents) avoiding the breakup of the corpse; (4) delay in decay rate; and (5) bioprecipitation (Briggs, 2003a). The relevance of bioinduced precipitation (e.g., calcium carbonate) has been highlighted by several sedimentological and microbial ecological studies (Kühl et al., 2003; Decho and Kawaguchi, 2003; Dupraz and Visscher, 2005; Ludwig et al., 2005).

Accordingly, the preservative action of bacteria occurs during early biostratinomic phases, and actualistic approaches need to be designed to explore the role of biofilms in fossilization. Most experiments have used single-layered biofilms (e.g., experiments on Diptera, Peñalver, 2001; Echinoidea, Raff et al., 2008; and fish, Martín-Abad and PoyatoAriza, 2010). Analyses testing complex, multilayered biofilms (i.e., microbial mats) are rare (e.g., Crustacea, Briggs and Kear, 1994; Sagemann et al., 1999). We present herein an actualistic approach, in which specimens of the Teleostei fish Paracheirodon inessi (family Characidae) were placed on biomats that were previously grown in the laboratory. Neon tetra fish were monitored up to 27 months, tracking the sequence of changes during decay. The aim of this experiment is to contrast the role of microbial mats in the initial stages of exceptional preservation, and to examine how the organization, structure, and activity of this community influence the factors involved in preservation, and how these factors are interrelated.

\section{MATERIAL AND METHODS}

Microbial mats used in the experiment were obtained from samples from La Salada de Chiprana (Zaragoza, Spain), which is a hypersaline (30\%o-70\%o), permanent, and shallow lake of endorheic origin in a semiarid region of the Ebro depression (Aragon, northeastern Spain). Salinity arises from the continuous arrival of mineralized water containing magnesium sulphate and sodium chloride, which are the main salts in this environment. Microbial mats, enhanced by the extreme physical and chemical conditions of the lake, cover the sediment from the shoreline to a water column depth of $1.5 \mathrm{~m}$ (Guerrero et al., 1991). Cohesion of the mat is conferred by the main filamentous cyanobacteria, Microcoleus chthonoplastes.

The Chiprana mats were grown in the laboratory under controlled conditions. Glass tanks measuring $50 \times 25 \times 20 \mathrm{~cm}$ containing a $2-3 \mathrm{~cm}$ base of limestone overlain by a $3-4 \mathrm{~cm}$ layer of sediment from $\mathrm{La}$ Salada were used for mat development. Natural mat samples were ground up with a basic mixer (T25 IKA Labortechnik) and placed evenly over the sediment. Three of the tanks were illuminated by a $50 \mathrm{~W}$ halogen lamp (OSRAM Decostar 46870WFL). Incident illumination on the sediment surfaces was approximately $300 \mu \mathrm{mols} \mathrm{m}^{-2} \mathrm{~s}^{-1}$ $\left( \pm 1 \mu\right.$ mols $\left.\mathrm{m}^{-2} \mathrm{~s}^{-1}\right)$ intensity. Tanks were exposed to a $10 \mathrm{~h}$ dark, $14 \mathrm{~h}$ light cycle. A fourth tank, without a mat, was kept in darkness as a control. Although it would be preferable to subject the control to the 
same diurnal cycle, the control chamber was kept in the dark to avoid mat growth from resistant phototrophic bacteria in the natural sediment. The mats were allowed to grow until they stabilized, exhibiting a structure and composition similar to those of natural mats. Conductivity (as an indirect measured of salinity), temperature, and $\mathrm{pH}$ were monitored in the course of the experiment (measured with a WTW-LF 330/SET conductivity meter and a 323 A WTW pH meter, respectively).Water conditions in the tanks were maintained at $27{ }^{\circ} \mathrm{C}$ $\left( \pm 0.5{ }^{\circ} \mathrm{C}\right), \mathrm{pH} \quad 7.9( \pm 0.2)$ and conductivity $57.1 \mathrm{mS} \mathrm{cm}^{-1}$ $\left( \pm 2.3 \mathrm{mS} \mathrm{cm} \mathrm{cm}^{-1}\right)$. Sterilized distilled water was added each day to maintain a 2-cm-deep layer of water and constant salinity.

Paracheirodon inessi fish (neon tetra) were used as experimental animals. Specimens were analyzed (one from each microbial tank and two from the control tank) at 7, 15, 30, 45, 60, and 90 days. Additionally, several fish were kept longer in the mat to make subsequent observations possible. At days 120, 270, 540, and 810, fish from both kinds of tanks (with mat and control) were extracted to observe the entombment and decay state (see Long-Term Monitoring section). Specimens were chosen at random to maintain objectivity. Paracheirodon inessi was chosen on the basis of its morphological characteristics, which can be conveniently assessed during the decay process (e.g., large eyes that enable decay to be monitored, color to control the loss of brightness, scale organization) and size $(2.3 \pm 0.4 \mathrm{~cm}$ long). Following standard animal care protocol used at the Universidad Autónoma de Madrid, fish were asphyxiated with nitrogen and laid on the microbial mat or nonmat sediment, with a $2.5 \mathrm{~cm}$ gap between specimens to avoid possible interactions. This distance was established with preliminary experiments, in which there was no intersection of the sulphide halos between adjacent fish. A range of quantitative and qualitative observations of these samples was made, according to the proposed objectives: (1) comparative measures of decay in the mat and control sediment samples; (2) the biostratinomic processes associated with entombment in complex mats; and (3) long-term monitoring of internal and external fish integrity.

Fish were manipulated by cutting a thin lamina of the mat and separating the carcass from the mat under the stereo microscope. For the control, fish were removed with a small spatula, in order to minimize damages, and cleaned with drops of water. Qualitative observations (see below Entombment and biostratinomic processes) were based on the changes in fragility of the decaying fish according to handling.

\section{Comparative Decay Measure}

As discussed above, fish were examined from each of the mat tanks and the control tank at set intervals. Decay was monitored to establish the sequence of decomposition, observing the following biostratinomic alterations: body-head connection, caudal and dorsal fin disarticulation, loss of coloration, scale organization, and eye decay (Fig. 1-2). The variables selected are based on analyses of tetrapod disarticulation sequences (Cambra-Moo and Buscalioni, 2003), wherein the biostratinomic alterations tracked the modular body organization (body-head; fins or appendages connections) rather than occurring randomly. Decompositional characteristics were scored as: 0 , no changes; 1 , light changes; 2, partial modification; 3, total modification. Data from mat and nonmat sediment samples were subjected to a Hierarchical Cluster Analysis using SPSS 15.0 for Windows. The results are represented as a dendrogram (Fig. 3).

The metric comparison was based on the length, width, and thickness of fish, making it possible to determine whether the mat has an influence on decay rate. These measurements were made with a $150 \mathrm{~mm}$ digital caliper. Measurements were taken before the animals were placed on the mat and on each of the aforementioned dates. The morphometric data were subjected to an Analysis of Variance (ANOVA) to determine whether the microbial mat was a significant factor in decay rate.

\section{Early Entombment and Initial Biostratinomic Processes}

To follow the envelopment process, the growth of microbial mat over fishes was monitored. Bodies were observed with the aid of an Olympus SZX ILLK200 binocular microscope and photographs were taken with an Olympus Camedia C5050 Zoom digital camera. Detailed observations were made of modifications of the eyes, fins, and scales using a Hitachi S-3000N Scanning Electronic Microscope (SEM). Samples were fixed with glutaraldehyde $2 \%(4 \mathrm{~h})$, osmium tetroxide $1 \%(4 \mathrm{~h})$ and dehydrated in an alcohol series of increasing concentrations (30\%, 50\%, $70 \%, 90 \%, 3 \times 100 \%, 5 \mathrm{~min}$ each). Solutions were prepared with PBS (phosphate-buffered saline), and some residue remained after washing. Samples were dried at $37^{\circ} \mathrm{C}$ overnight. To facilitate SEM observations, the entire bodies were covered with gold to make electron conduction easier. During observation under the SEM, bioprecipitates were localized and occasionally examined using Energy Dispersive X-ray analysis (EDX, with an INCA X-sight analyzer; Oxford Instruments). This makes atomic identification (and estimation of percentage of weight) of eventual superficial precipitates possible. Carcasses were separated from the microbial cover to reveal the coating formed by the cyanobacteria and any mold that may have formed on the carcass, taking care not to disrupt the shape of the body. In four cases, longitudinal and sagittal sections were examined to observe and describe fish shape, the interface with the mat, and any possible changes on the mat and the surface of contact between the fish and its surroundings.

\section{Long-Term Monitoring}

After entombment in the mat, manipulation of the fish became difficult, making extraction impossible. New techniques, such as magnetic resonance imaging (MRI), were utilized to continue to observe taphonomic alteration of the specimens. MRI is a nondestructive technique that provides good contrast between the body parts and tissues. Two fish were taken from the mat after 270 days to analyse coverage. These fish and two additional fish at day 810 were removed from the tank with their intact microbial envelopment to evaluate morphological integrity. Integrity was studied using a Bruker BMT 47/40 MRI scanner (see Grimm et al., 2003; Riches et al., 2009 for the MRI technical application). MRI samples were compared with a control fish ( 9 months on nonmat sediments) and with a recently killed fresh fish. T2-weighted MRI was chosen to obtain the best possible contrast between the fish and the microbial mat. Contrast results from differential magnetic excitation of protons contained in water. Due to energy gained by excitation, higher hydration appears lighter in the image and less-hydrated tissue appears darker (Novelline, 2004).

\section{RESULTS}

\section{Sequence of Changes During Decay}

Monitoring the decomposition revealed important differences in the decay sequence between fish placed on the microbial mat and on nonmat sediment (Fig. 1). The variability in the decay sequence among specimens at each sample date was very low. Control fish showed advanced decay from the second week. At day 15, the exposed side of the fish exhibited substantial damage, the eye presents moderate decomposition (Fig. 1B), and the fins are considerably disarticulated (Fig. 1D). Subsequently, the decomposition of the fish became so advanced (Fig. 1F, day 30) that during manipulation for analysis the head became disconnected from the body and the carcass was reduced to several fragmentary remains, such as isolated bones from the spinal cord. In contrast to the control, fish from mat tanks exhibited only minor damages. Between days 7 and 30, the structural integrity of the fish did not alter. The fins and abdomen were trapped by cyanobacterial 

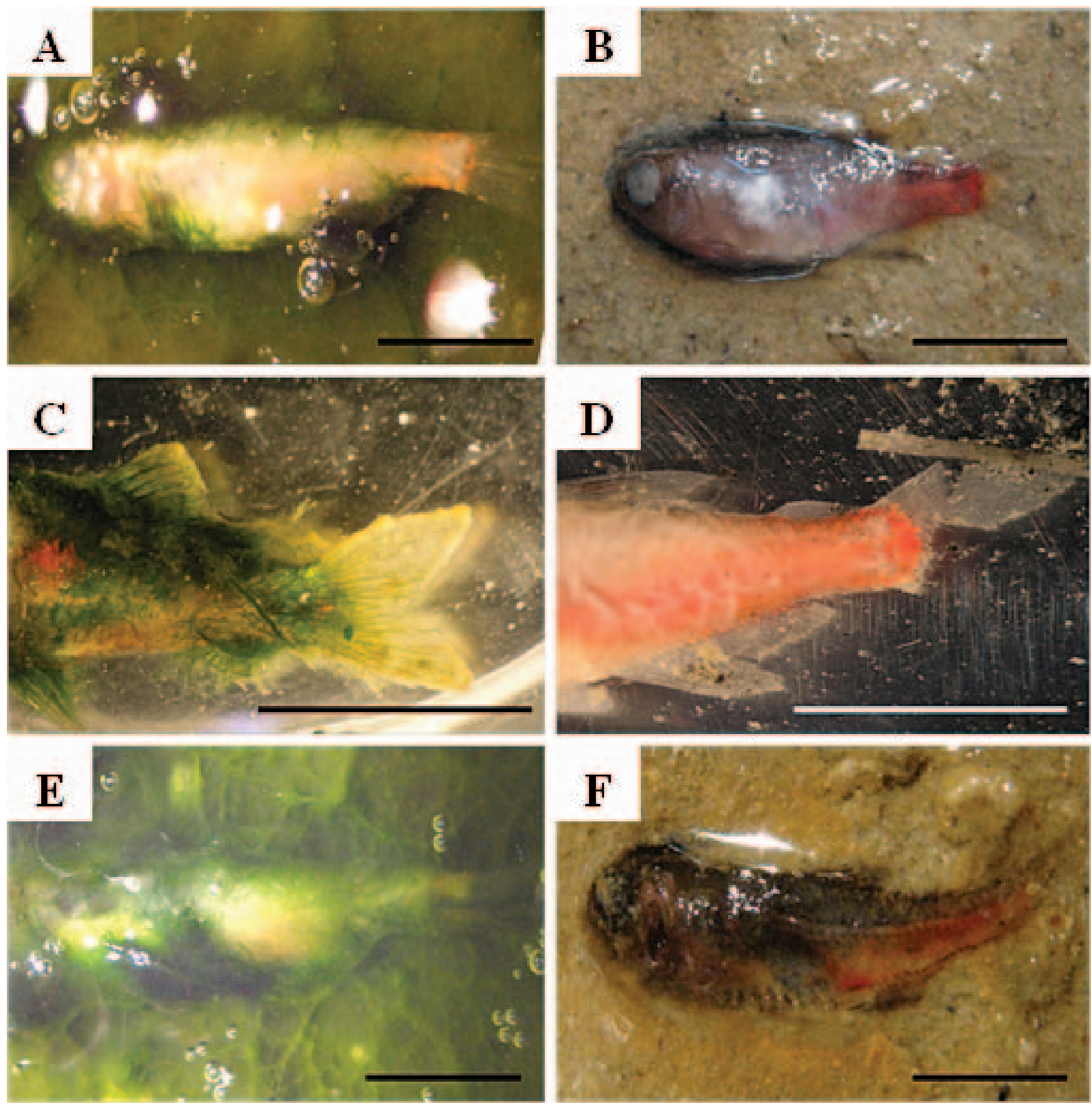

FIGURE 1-Sequence of changes caused by decay when fish is laid on microbial mat or on sediment. A) Fish on microbial mat on day 15; B) fish control on sediment on day 15 (note that the sediment below has turned black because of anoxic conditions caused by decay); C) on day 15 , detail of caudal fin partially covered by mat, completely articulated and D) state of decay of caudal fin of fish control on day 15. E) Fish covered by mat on day 30, retaining initial morphology, and F) fish on sediment after 30 days. (Scale bar represents $0.5 \mathrm{~cm}$ ).

filaments (Fig. 1A) and by day 15, filaments had begun to grow over the whole body (Fig. 1C). In these initial days, several fish (30\%) exhibited a hole in their abdomen, due to the production of gas by intestinal bacteria during the bloating phase. At day 30 the fish were almost totally covered by microbes (Fig. 1E). After this day, fish on the mat showed only slight changes in some structures, such as the fins, and color.

Scanning Electronic Microscopy (SEM) was used to detail the biostratinomic changes of the eyes, fins, and scales between fish on mat and nonmat sediment (Figs. 2A-D). The upper eyeball of the fish on the mat (Fig. 2A) was complete, whereas that of the fish from the control tank was substantially deteriorated (Fig. 2B). Dorsal fins also differed. Whereas the fins from control fish were rapidly disarticulated and the fin rays were fractured (Fig. 2D), the microbial mat fish maintained imbricated scales and articulated fins devoid of broken elements (Fig. 2C). Over time the differences became more pronounced. By day 30, the microbial mat fish retained their integrity with articulated scales and no pierced surfaces or holes (Fig. 2E), whereas the scales of the control fish were disarticulated and exhibited many holes (Fig. 2F). On day 90 the microbial mat specimens still maintained organized scales and tegument (Fig. 2G), while the control specimens were decomposed, with only a few fragmentary and unconnected remains (Fig. 2H). At this point further observation of the remains was of no comparative value. The integrity observed in fish extracted from the mat after this time revealed that their articulation was not caused by 

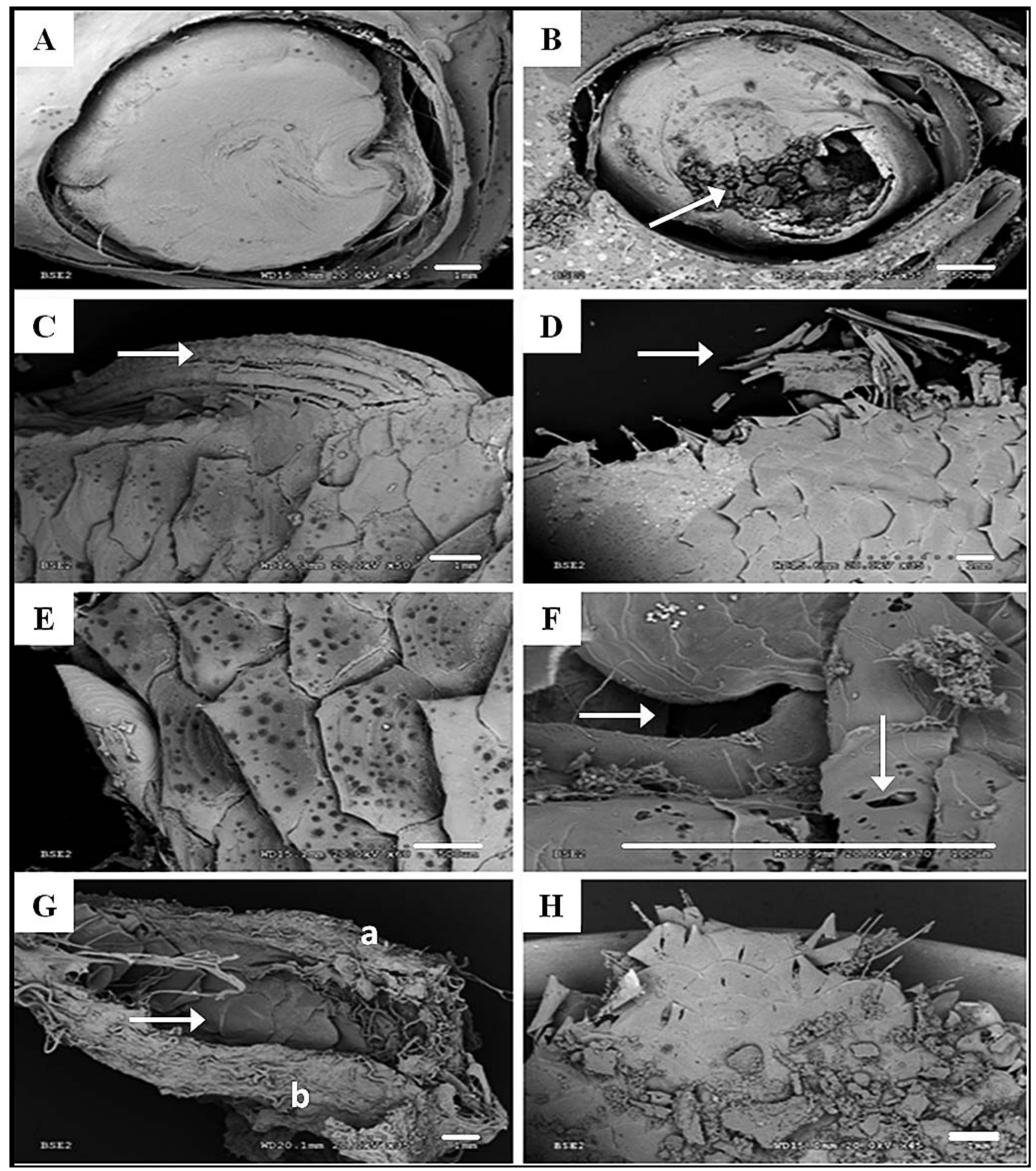

FIGURE 2-SEM monitoring of the changes experienced by individuals during decomposition. Left- and right-hand columns correspond to samples on mat and on sediment, respectively. A-B) detail of the fish's eye on day 7. The arrow marks the alteration of the eye in the control fish (arrow). C-D) Detail of the dorsal fin (arrows) on day 7. E-F) Detail of the fish's scales on day 30. F shows nonoverlapping and perforated scales. Dark blots in E are due to osmium tetroxyde precipitates. G) Fish removed from the mat on day 90. Cut in the microbial coverage ( $a$ and $b$ ) enables observation of scales (arrow). The tegument is not broken or pierced and the integrity of the fish's body is maintained (no disarticulation observed), in spite of the damage caused by manipulation. H) Detail of caudal fin on day 90. (Scale bar represents $250 \mu \mathrm{m}$.)

the binding effect of the mat but rather that the remains retained a natural coherence separate from the mat.

Based on qualitative data collected during observation (Table 1), hierarchical cluster analysis shows the percentage similarity of the sampled fish, classifying the corpses with a similar decomposition pattern into the same group. Figure 3 shows the strong difference between control and microbial mat fish. The control cluster contains fish from the control tank up to day 15 . All the control fish, from day 30 to 90 , are located in a subcluster denoting a similar, and advanced, stage of decay, which is further divided into two groups, depending on 


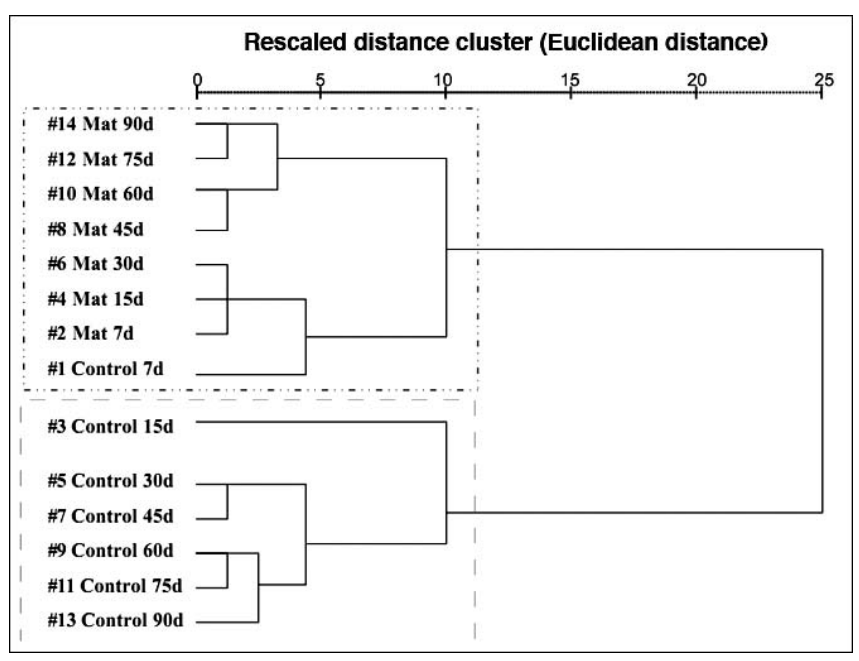

FIGURE 3-Dendrogram obtained by hierarchical cluster analysis. The graph shows the differences in decay between the control fish and the microbial mat fish, which are separated in two clusters. Only control sample \#1 (7 days) is placed in a cluster containing fish from the microbial mat samples, owing to the fact that initial differences in decay are not significant until after day 15 .

the decay time. Fish covered by microbial mats are grouped in a separate cluster. In this case, decay appears with a singular order, split into three groups: fish from (1) day 1 to 30; (2) days 45 and 60; and (3) days 75 and 90. Interestingly, the subcluster containing fish from days 1 to 30 was grouped with control fish \#1, the only control sample that is not grouped in the decomposed cluster (see Discussion). In fact, decay on control fish \#1 was not noticeable. The three groups of microbial mat fish indicate progressive decay that follows a temporal sequence. The microbial mat fish did not attain a state of advanced decomposition comparable to that of the control fish within this experiment. Comparison between the control and the microbial mat fish was impossible after day 90 because of the advanced state of decomposition that characterized the remaining control fish.

The morphometric variables analyzed provide a good proxy for decay. Loss of thickness, for example, is a reliable variable because it may reflect decay collapse. ANOVAs of length, width, and thickness, using time and decomposition as the explanatory variables, show that the percentage loss of each variable is indicative of the influence of the mat on the decay rate (in all cases, $\mathrm{P}<0.001$ ) (Fig. 4). All morphological variables were influenced by time and decomposition setting (i.e., microbial mat versus sediment). Both microbial mat and control sediment tanks exhibited a similar development until day 15. The data show that significant decay occurred after day 15 (Fig. 4), and illustrate why the control sample \#3 (day 15) is separated in the dendrogram from the subcluster containing control samples from day 30. On day 15, although the state of decay of the control fish was more advanced than that of the microbial mat fish, decay is not of the same magnitude as exhibited by subsequent control samples. This phase may be characterized by changes due to internal microorganisms (bloating phase) (Cambra-Moo et al., 2008). Although the bloating effect may have masked the loss of volume (length, width, and thickness), other qualitative observations reinforced a delay of 15 days before significant decay began. Subsequently, the differences in loss of volume increase, showing that decay in control samples in sediment becomes increasingly important through time, while decay is delayed in the microbial mat fish.

\section{Early Entombment and Initial Biostratinomic Processes}

Two main structures are involved in covering the body of the microbial mat fish: a) a calcium-rich film, and b) the woven cyanobacterial layer that forms a sarcophagus. The interrelationship of these two structures was difficult to observe because of the techniques employed for analyses (i.e., precipitation was monitored by SEM, while cyanobacterial entombment was examined with a stereomicroscope).

The importance of the natural formation of precipitates in mats has led to them to be regarded as essential to fossilization (i.e., bioinduced phosphatization, Briggs et al., 1993; Wilby et al., 1996; mineral replacement processes, Dunn et al., 1997). EDX showed that calcium carbonate was the main compound precipitated in mats (Fig. 5B), even though the Chiprana water is sulphate- and magnesium-rich. The precipitates of the control sediment are representative of the water composition $\left(\mathrm{MgSO}_{4}\right.$ and $\left.\mathrm{MgCl}_{2}\right)$. Calcium precipitates were incidental and relatively poor. In contrast, Ca-rich precipitates appeared on day 7 on the carcass surface of the microbial mat fish. Small spherules of precipitates occurred in patchy regions of the surface of the fish (Fig. 5A). These spherules may have promoted the formation of a calcium coat that became a thin film by day 15 covering the whole carcass (Figs. 5C and D). The calcium enrichment of this coat was evident when broken areas of the film were analyzed (Figs. 5E and F). This calcium carbonate coat was initiated before the entire body became covered by cyanobacteria. This initial carbonate precipitation was likely induced by the photosynthetic mat activity and the degradation of the extracellular polymeric substances (EPS) (Decho and Kawaguchi, 2003).

The growth of the microbial mat was inspected on days $7,15,30,60$, 90, 120, 270, and 540. Figure 6 shows entombment (i.e., the covering and entrapment of the carcass by cyanobacteria), and the progressive

TABLE 1-Sequence of changes observed during the process of decomposition of fishes in nonmat control sediment and tanks with microbial mats. $0=$ no changes observed; $1=$ minor changes observed (i.e., some rays of the fin are broken); 2 = moderate decay; 3 = major decay observed (i.e., loss of color, loss of articulation).

\begin{tabular}{|c|c|c|c|c|c|c|c|}
\hline Sample time (days) & Tank & Color & Head-body connection & Eye & Caudal fin & Dorsal fin & Scales \\
\hline 7 & Nonmat & 1 & 0 & 1 & 1 & 1 & 0 \\
\hline 7 & Mat & 0 & 0 & 0 & 0 & 0 & 0 \\
\hline 15 & Nonmat & 2 & 2 & 2 & 2 & 2 & 1 \\
\hline 15 & Mat & 0 & 0 & 0 & 0 & 0 & 0 \\
\hline 30 & Nonmat & 3 & 3 & 3 & 3 & 2 & 2 \\
\hline 30 & Mat & 0 & 0 & 0 & 0 & 0 & 0 \\
\hline 45 & Nonmat & 3 & 3 & 3 & 3 & 3 & 2 \\
\hline 45 & Mat & 0 & 0 & 0 & 1 & 1 & 0 \\
\hline 60 & Nonmat & 3 & 3 & 3 & 3 & 3 & 2 \\
\hline 60 & Mat & 0 & 0 & 0 & 1 & 1 & 0 \\
\hline 75 & Nonmat & 3 & 3 & 3 & 3 & 3 & 2 \\
\hline 75 & Mat & 0 & 1 & 0 & 1 & 1 & 0 \\
\hline 90 & Nonmat & 3 & 3 & 3 & 3 & 3 & 3 \\
\hline 90 & Mat & 1 & 1 & 0 & 1 & 1 & 0 \\
\hline
\end{tabular}



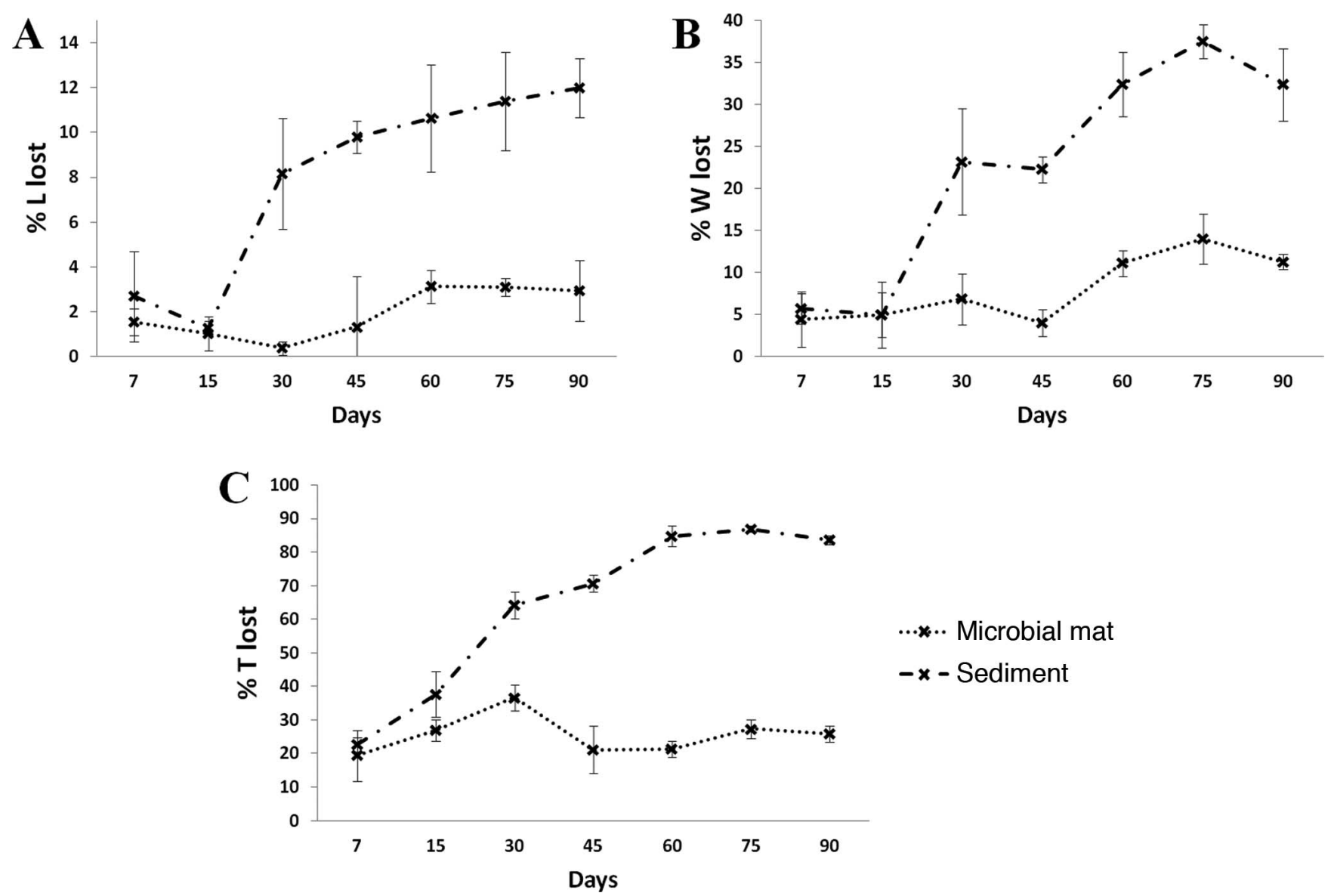

FIGURE 4-Variation of dimensions measured in fishes placed on the microbial mats and nonmat control sediments. Measurements were taken before the animals were placed on the mat and on each of the aforementioned dates over the experimental period (average, bars represent SD). After an initial delay of 15 days, an important loss of volume is registered in control samples, in opposition to the volume of samples from microbial mats. A) Variation in length, B) variation in width, C) variation in thickness.

formation of a sarcophagus that reproduces the shape and size of the body. Cyanobacterial filaments start to weave a superficial green net on the body surface at day 15 (Fig. 6B), covering most of the body by day 30 (Fig. 6C). The observations made on days 270 ( 9 months) and 540 (18 months) illustrated that the fish had maintained integrity, with respect to tegument continuity, articulation and connectivity, and threedimensional shape. The mat community that formed over the fish thickened over time. The fish was fully immersed in the mat at the interface of the green (oxic) and red (anoxic) layers (Fig. 6D) by day 270. At the time of the next observation (day 540, Fig. 6E) the fish was fully incorporated into the red anoxic layer.

\section{Long-Term Monitoring}

To determine the extent to which the integrity is maintained throughout the initial biostratinomic stages, MRI samples (day 270 and day 810) were compared with a recently dead individual (Fig. 7A). MRI of mat fish reflected its external integrity, and strikingly, the fish preserved its internal skeletal organization and soft organs. In an MRI of the control fish, only medullar and eye fragments were recorded. The control fish later provided an obscured, weakly contrasted image, contrary to the perfectly contrasted microbial mat fish (Fig. 7D). The contrast reflects the hydration level of the inner organs (e.g., sclerocorneal capsule, swim bladder, and muscle somites) indicating that decomposition is much slower under these circumstances (Figs. 7B and E). Nevertheless, the contrast faded for the 810-day microbial mat specimen (Fig. 7C). At that stage, the microbial growth over the body was probably already compressing it, thereby explaining its loss of volume and its dehydration.

\section{DISCUSSION}

\section{Experimental Outcome}

Microbial mats need to be grown for a long period of time for their complex structures to fully develop. Few experiments have been carried out specifically with vertebrates in continental microbial mats. Most of the taphonomic analyses of fish have involved marine environments (Viohl, 1994; Bieñkowska, 2004; Esperante et al., 2008), although there are a few exceptions (Mancuso, 2003; Martín-Abad and Poyato-Ariza, 2010). In addition, these previous investigations used single-layered biofilms. Therefore, it is somewhat difficult to establish a comprehensive referential framework to discuss comparatively and in detail the resulting biostratinomic changes.

Fish fossils commonly occur within the habitat wherein their carcasses are found, and hence are important for inferring environmental conditions (Wilson, 1988). Thus, the analysis of carcasses in sediment covered with water and on microbial mats introduces new elements to the study of fish taphonomy in exceptional deposits. Our experiment helps to establish a firm basis for the framework needed for collecting data (i.e., sample size necessary to enable changes in sediment fish to be compared, and also more natural experimental conditions). Long-term observations in particular are based on only a few analyzed samples. Within our experiment, MRI analyses were instrumental in determining the coherence of fish carcasses entombed in microbial mats for periods up to and exceeding two years.

It has been postulated that the presence and activity of microbial mats plays a key role in the optimal conservation of remains. Factors inferred rather than tested in microbial mats (i.e., protection, delayed 


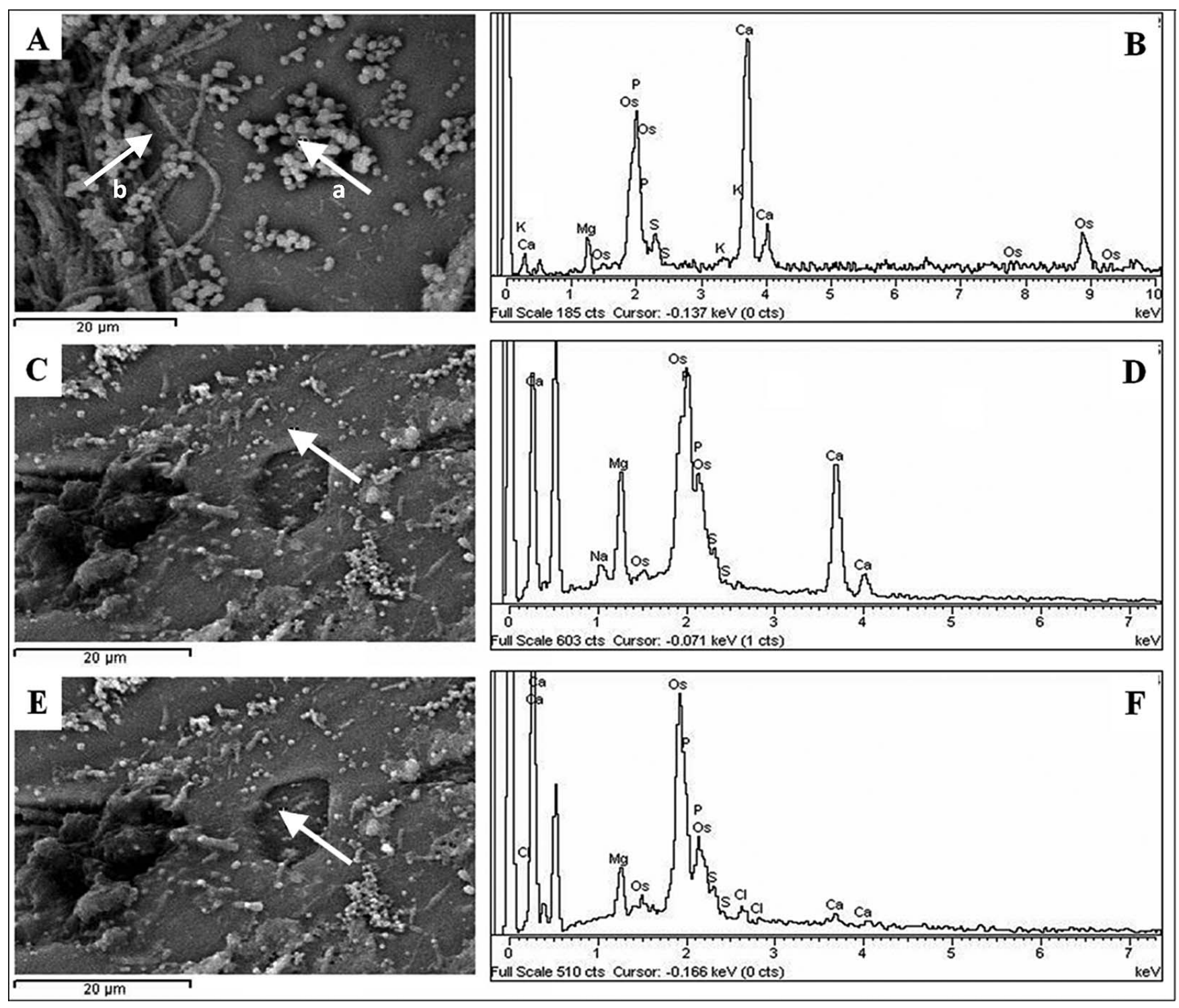

FIGURE 5-SEM image showing precipitates over the surface of fish on microbial mat. A) Spherules of precipitates (arrow a) on fish after 7 days. Arrow $b$ shows some filamentous cyanobacteria. B) EDX analysis of the precipitate of fish illustrated in A. C) Ca-enriched film on day 15 (arrow). D) EDX analysis of the precipitate of fish illustrated in C. E) Hole in the film (arrow) showing a surface poor in Ca after 15 days. F) EDX analysis of the precipitate of fish illustrated in E. Presence of osmium tetroxide and phosphate in samples is due to fixation. Signal numbers correspond to the area analyzed. White arrow shows the point analyzed by the EDX.

decay, and mineralization) have been presented as necessary conditions for preservation (Gall, 1990; Wilby et al., 1996; Gehling, 1999; Briggs, 2003a, Briggs et al., 2005; Martill et al., 2008). However, previously there was neither direct information nor experimental description of the temporal sequence of the processes in which microbial mats develop and contribute to carcass preservation.

Even if a fish corpse floated for an interval prior to settling on a benthic mat, 15 days elapsed before notable decomposition occurred (Fig. 3). Obviously, the time interval depends, in part, on the water composition. For instance, it has been inferred that saline water should delay bacterial growth (Martill et al., 2008; Martín-Abad and PoyatoAriza, 2010). Once the fish is on the surface of the mat, EPS and filamentous cyanobacteria contribute to attach the corpse to the mat. This process is different from transport and trapping of the body to the sediment by single-layered biofilm, as has been described elsewhere (Martínez-Delclòs et al., 2004). This simple biofilm grows over carcasses and sinks the body, but it is not implicated in fixation to the bottom. At this phase, gas production may help to refloat corpses. Therefore, quick fixation and the coating process (from day 15) appear to be two major factors preventing disarticulation. Rapid burial by sediment may significantly prevent decay as well (Seilacher et al., 1985). Because the control fish were kept subaerially during this experiment, the influence of rapid burial by sediment was not contrasted.

Ca-rich precipitates on the body surface occur as soon as coverage begins. These results are consistent with previous sedimentological and ecological experiments that demonstrate the involvement of microbial activity in $\mathrm{CaCO}_{3}$ precipitation, even in the absence of carcasses (Kühl et al., 2003; Dupraz and Visscher, 2005; Dupraz et al., 2009). The observed precipitated particles (Fig. 5A) are organized in a similar way to those $\mathrm{CaCO}_{3}$ spherules formed by induced bioprecipitation (Krumbein et al., 1977; Decho and Kawaguchi, 2003). EPS produced by microbes seem to be closely related to this process. During microbial production and secretion of these compounds, $\mathrm{Ca}$ and other ions are sequestered. When EPS become degraded, these minerals are released into the environment (water). This sudden increase in the concentration of these elements would exceed the maximum (saturation), making precipitation easier (Kühl et al., 2003). O’Brien et al. (2002) hypothesized, from observations of exceptional insects and fossil 

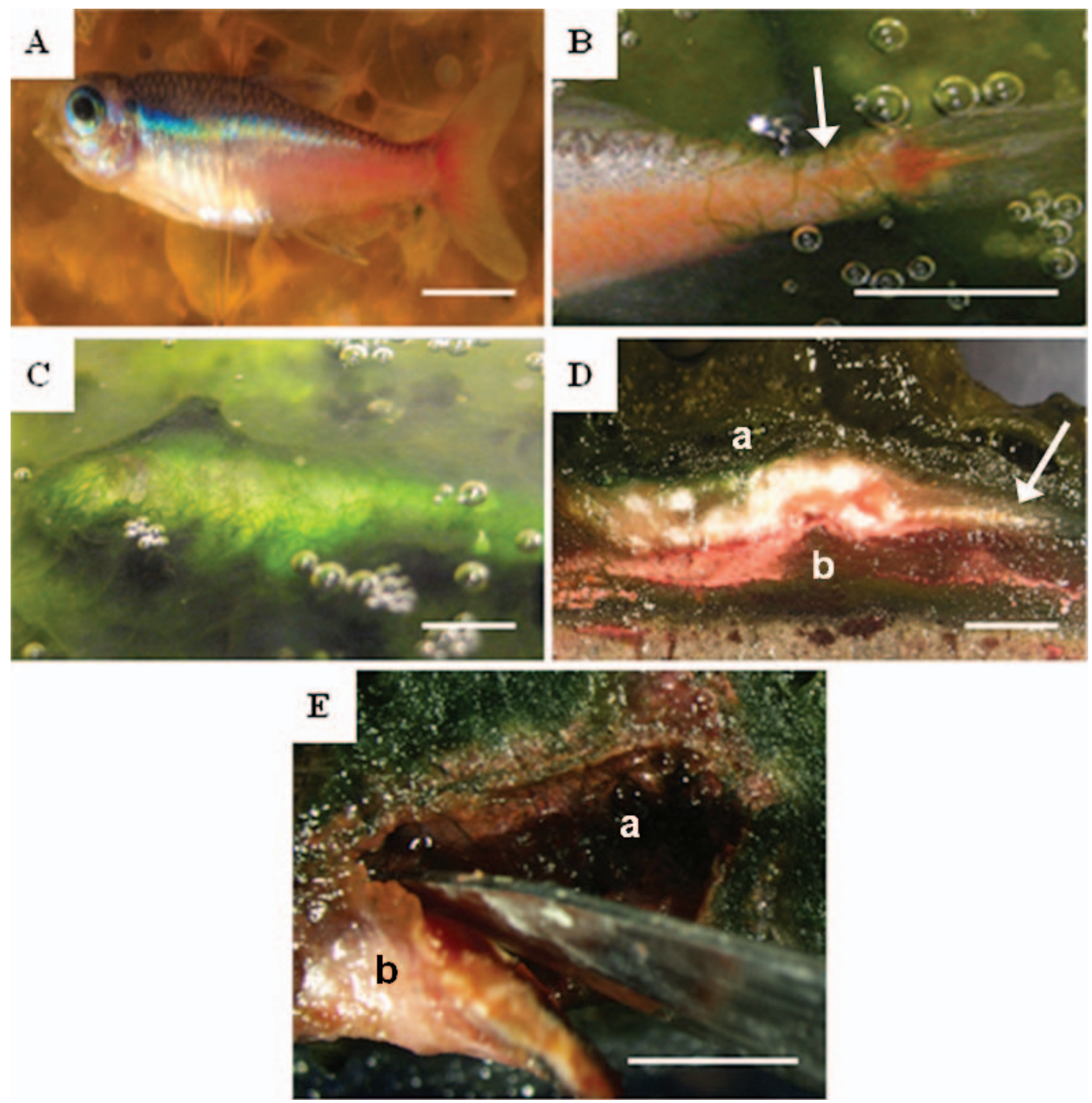

FIGURE 6-Coating process. A) Fish on mat at the beginning of the experiment. B) Caudal fin trapped by filaments (arrow) at day 15. C) Fish totally covered by microbial mat at day 30. D) Coronal cut of the fish on microbial mat at day 270 (9 months). Profile shows stratification of mat and position of fish between cyanobacterial (a) and red layers (b). Identification of some fish bones (as vertebrae) is still possible (arrow). E) Fish being removed from mat (b), revealing the mold formed by microorganisms (a) (day 540,18 months). (Scale bar represents $0.5 \mathrm{~cm}$.)

plants, that EPS would probably be decisive in preservation. This experiment provides evidence that EPS plays an important role because carbonate precipitates precede the cyanobacterial net. The formation of these spherules may be related to the construction of an integral carbonate film. This kind of film maintains the structure of the corpses, forming a microenvironment that surrounds them, reducing the decay rate and promoting mineralization and the formation of molds. The formation of such an extended calcium film covering rather large bodies would not be possible in single-layered biofilms. Previous observations by Peñalver (2001) demonstrated that the microbial photosynthetic single-layered biofilms formed over floating carcasses do not resist turbulence and thus lose their integrity. This difference between microbial mats and single-layered biofilms is one of the most important factors in the difference between these structures in carcass preservation.

The green microbial mat cover may eventually become a sealed sarcophagus. In such a situation the degree of protection is significant. In the natural environment, this protection would make scavenger attack or erosion and transport by natural currents difficult. Thus envelopment by microbial mats is a key factor preventing disarticulation, as suggested by O'Brien et al. (2008). The protection would also be influenced by the degree of hydration which is maintained by the mat embedded in water, and probably boosted by the presence of EPS. 

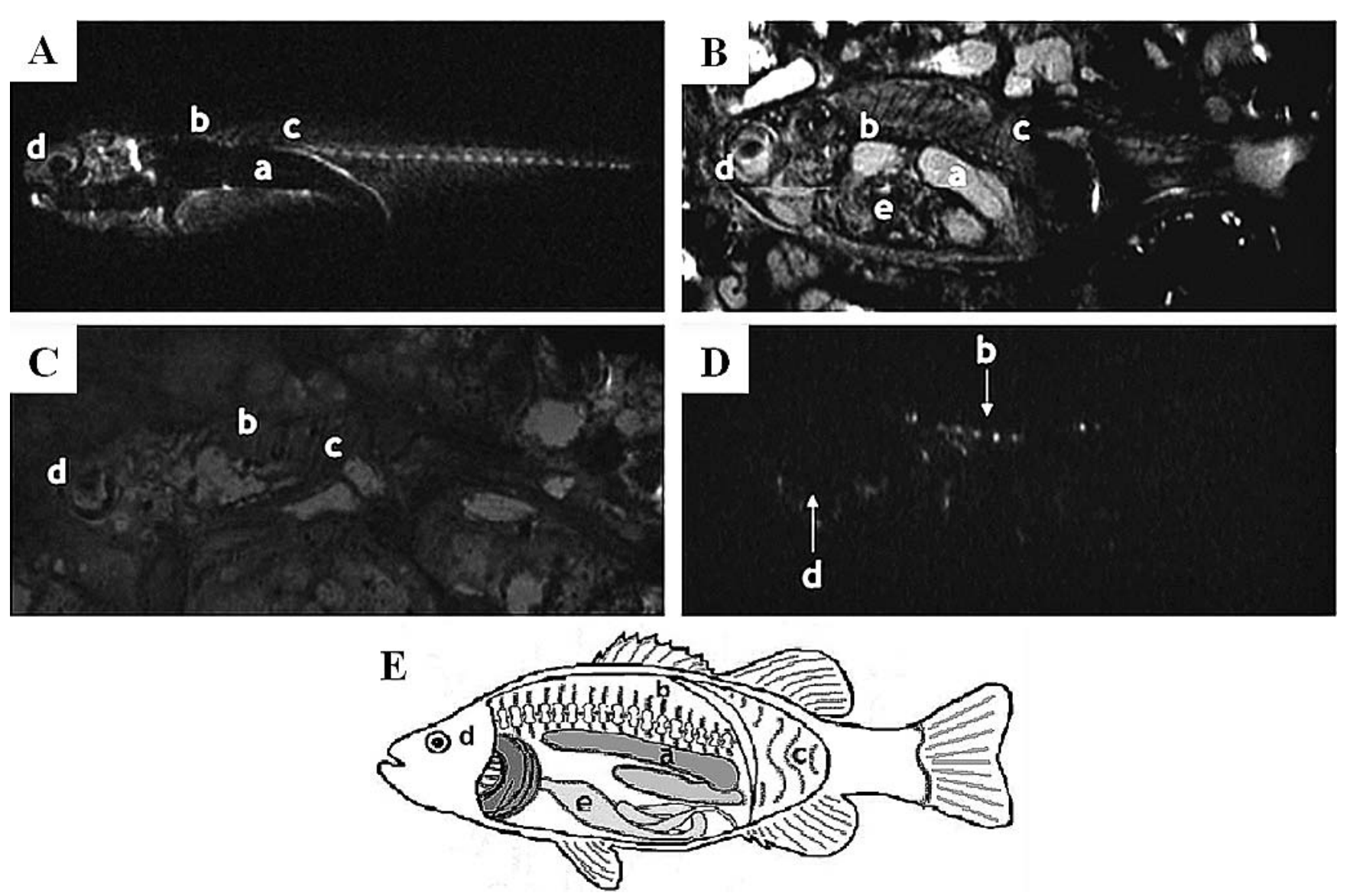

FIGURE 7-Magnetic resonance imaging of fish. Brightness of the observation reflects the degree of tissue hydration. In this T2-weighted scan, the water is shown as a light tone and the fat tissue in grey. A) Fish at the beginning of the investigation. B) Fish in microbial mat after 270 days ( 9 months). C) Fish trapped by mat after 810 days ( 27 months). D) Decomposed fish on control, sediment. Experimental time for this sample: 270 days. Only some sections of vertebrae and eye socket are visible (arrows). E) Sketch of the inner organization of the fish, for comparison with MRI observation. In this image: $\mathrm{a}=$ swim bladder; $\mathrm{b}=$ spinal cord; $\mathrm{c}=$ muscle; $\mathrm{d}=\mathrm{eye}$ sclerocorneal capsule; $\mathrm{e}=$ intestines.

Hydration appears also to be important to corpse integrity (discussed below).

Anoxia is another important factor for exceptional preservation. It minimizes disarticulation by reducing the decay rate and by preventing the activities of scavengers (Fregenal-Martínez and Buscalioni, 2009). Microbial mats can create anoxic conditions in three ways: (1) Because of their stratified structure, there is a compartment rich in reduced compounds beneath the green oxic layer. The decomposition rate is reduced in this compartment because anaerobic metabolism is less energetically efficient. In mats, the oxygen decay occurs at a depth of $1-$ $3 \mathrm{~mm}$ (even during light intervals) while in nonmat sediment the lack of oxygen occurs at a depth of $6 \mathrm{~mm}$. (2) Because the anoxic microbial layer prevents contact with the oxygenated water column or even the oxygen produced by the mat itself, the sediment under mats is in constant anoxic conditions. Under some conditions (for example, at night when photosynthesis enters a stand-by phase), reduced elements (such as $\mathrm{H}_{2} \mathrm{~S}$ ) from the sediment or the anoxic layer could make the entire water column (or at least its deepest zone) anoxic. (3) Due to the formation of a Ca-rich film, the carcass would be isolated and protected from oxygen produced by cyanobacteria.

Figure 8 summarizes the processes related to entombment and replication (corpse mold) of a fish carcass that promotes and enhances exceptional preservation. A biological coating of EPS and filamentous cyanobacteria quickly covers carcasses. After entombment, the microbial coverage preserves the shape and integrity of the organic material, providing protection against abiotic agents (wind, water flow). Biological degradation is avoided, removing the fish from the surface and hiding the corpse. This protection is amplified by the anoxic conditions that are inherent to microbial mat organization. In addition, anoxia affects the delay in the decomposition rate and induces carcass replication promoting bioprecipitation of $\mathrm{Ca}$ compounds. This slowdown in the rate of decomposition spans the time for replacement and mineralization of the remains favoring preservation.

\section{Implications for Fossil Preservation}

The principal taphonomic implication of the role of microbial mats is preservation in the first stages of fossilization and body integrity. These

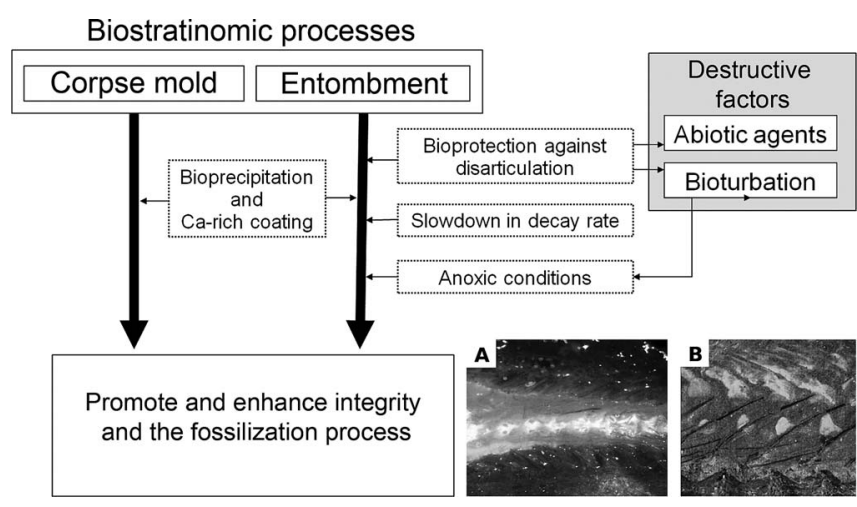

FIGURE 8-Diagram summarizing the role of microbial mats in exceptional preservation. A) Detail of caudal fin of a fish covered by microbial mat after 9 months. B) Fossil found at Las Hoyas (Spain) showing somite organization. 
initial stages, subject of this paper, are essential in fossilization, regardless of the deposit properties (fossil composition, organic origin, mineralization, chemical and physical conditions). We apply the term integrity to those features (tegument continuity, connectivity, and three-dimensional shape) that are necessary for exceptional fossilization. While carcasses on nonmat sediment lose their consistency, becoming unstructured after day 30 , bodies in microbial mat preserve their integrity and remain coherent. Morphometric analysis revealed that fish on microbial mats maintained, to a large extent, their original size and volume (length, width, and thickness) over the experimental period (3 months for quantitative analysis and 27 months for observational description) and this differed notably from the control. Integrity may also be associated with the nature of the water. Salinity (particularly hypersalinity) has been suggested as a factor for fish death and exceptional preservation (Bieñkowska, 2004; Martill et al., 2008). Results of experiments comparing fish decomposition in marine and fresh water tanks show that body integrity is apparently higher in marine water, but carcass turns to a gel when perturbed (Martín-Abad and Poyato-Ariza, 2010). Thus, water alone cannot be considered a contributing preservation factor; other external conditions related to burial must also be met. Integrity is also favored by formation of a microbial mat sarcophagus and encasement by a calcium-rich film. These two factors enable the maintenance of the three-dimensional organization (preventing flattening), hydration, and anoxia. MRI images show that after 270 and 810 days the integrity of external and internal organs did not significantly change. The tegument was not pierced and the fish remained fully articulated. Furthermore, a clear outline of the fish's inner organs, such as the sclerocorneal capsule of the eye, the swim bladder, and muscle somites, were still present and visible due to hydration. Although at day 810 the fish was less hydrated (the MRI image was not sharply contrasted; Fig. 7C) and the body was more flattened (35\% of thickness lost), this flattening was gradual and occurred before compression induced by burial. These gradual changes (slow decay) are important for keeping the body in the best preservation condition (Briggs et al., 1997).

In summary, the role of microbial mats at the initial stage of fossilization is related to a set of favorable conditions of preservation, namely the absence of physical distortion, necrokinesis (lateral transport), disarticulation, or dispersion of elements. These favorable conditions are facilitated because microbial mats are involved in distinct biostratinomical processes: (1) biostratinomic encrustation, which involves the envelopment by cyanobacterial filaments; (2) precipitation of calcium, which is promoted by EPS and leads to the formation of a calcareous concretion covering the carcass; (3) concretional mold formation (replicating the external shape of the fish). In fact, whereas concretional molds were not directly observed in our experiment, they have been noted elsewhere in studies conducted on shrimps under controlled laboratory conditions by Briggs and Kear (1993). Thus, the physicochemical properties of microbial mats ensure that these early preservational processes will take place regardless the environmental conditions of the deposits.

\section{CONCLUSION}

The experiments discussed herein provide a detailed description of the initial stages of fossilization under the influence of microbial mats. Differences in decay between fish specimens on microbial mats and in the control group become apparent after day 15. Fish on microbial mats exhibit a delayed decomposition, maintaining external body integrity. MRI permits the recognition of the exceptional preservation of the internal organization and soft organs in microbial mat fish after 27 months, whereas control fish were rendered down to a few disarticulated bones. The sequence of processes related to entombment and replication started with carcasses covered quickly by EPS and filamentous cyanobacteria. Microbial coverage provides protection against biotic and abiotic agents, boosted by the anoxic conditions inherent in settings where microbial mats commonly develop. Anoxic conditions delay decomposition and induce precipitation, promoting carcass replication. As a consequence, the interaction of all these factors (protection, anoxia, delay in decay, and bioprecipitation) are essential to promote and enhance integrity, and exceptional preservation, a common factor in all Konservat-Lagerstätten.

\section{ACKNOWLEDGMENTS}

This work, which is part of research project CGL-2009-11838-BTE and Junta de Castilla- La Mancha, and the research grant that enabled Miguel Iniesto to participate, were funded by the Spanish Ministry of Science and Innovation. SEM observation was made possible by SidI service (UAM) and MRI monitoring was performed at CAI de RMN (UCM). We are pleased to acknowledge two anonymous referees and Associate Editor Murray Gingras, whose comments and observations helped us to improve this manuscript. Special thanks to Phil Mason, Nur Villar-Quiles, and Zeeba Khan, who reviewed the English language of our original manuscript.

\section{REFERENCES}

Behrensmeyer, A.K., 2000, Taphonomy: 3.3.7. Terrestrial vertebrates, in Briggs, D.E.G., and Crowther, P.R., eds., Palaeobiology II: Blackwell Science Ltd., Oxford, UK, p. 318-321.

BieñKOwska, M., 2004, Taphonomy of ichthyofauna from an Oligocene sequence (Tylawa Limestones horizon) of the Outer Carpathians, Poland: Geological Quarterly, v. 48, no. 2, p. 181-192.

Briggs, D.E.G., 2003a, The role of biofilms in the fossilization of non-biomineralized tissues, in Krumbein, W.E., Paterson, D.M., and Zavarzin, G.A., eds., Fossil and Recent Biofilms: A Natural History of Life on Earth: Kluwer Academic, Dordrecht. p. 281-290.

Briggs, D.E.G., 2003b, The role of decay and mineralization in the preservation of soft-bodied fossils: Annual Review Earth Science, v. 31, p. 275-301.

Briggs, D.E.G., and Kear, A.J., 1993, Fossilization of soft tissue in the laboratory: Science, v. 259, p. 1439-1442.

Briggs, D.E.G., and Kear, A.J., 1994, Decay and mineralization of shrimps: PALAIOS, v. 9, p. 431-456.

Briggs, D.E.G., Kear, A.J., Martill, M., and Wilby, P.R., 1993, Phosphatization of soft-tissue in experiments and fossils: Journal of the Geological Society, v. 150, no. 6 , p. 1035-1038.

Briggs, D.E.G., Wilby, P.R., Pérez-Moreno, B., Sanz, J.L., and FregenalMartínEz, M., 1997, Mineralization of dinosaur soft tissue in Lower Cretaceous of Las Hoyas, Spain: Journal of the Geological Society, v. 154, p. 587-588.

Briggs, D.E.G., Moore, R.A., Shultz, J.W., and Schweigert, G., 2005, Mineralization of soft-part anatomy and invading microbes in the horseshoe crab Mesolimulus from the Upper Jurassic Lagerstätte of Nusplingen, Germany: Proceedings of Royal Society Biological Sciences, v. 272, p. 627-632.

Buscalioni, A.D., and Fregenal-Martínez, M.A., 2010, A holistic approach to the palaeoecology of Las Hoyas Konservat-Lagerstätte (La Huérguina Formation, Lower Cretaceous, Iberian Ranges, Spain): Journal of Iberian Geology, v. 36, no. 2, p. 175-204.

Cambra-Moo, O., and Buscalioni, A.D., 2003, Biostratinomic patterns in archosaur fossils: Influence of morphological organization on dispersal: Journal of Taphonomy, v. 1, no. 4, p. 247-296.

Cambra-Moo, O., Buscalioni, A.D., and Delgado-Buscalioni, R., 2008, An approach to the study of variations in early stages of Gallus gallus decomposition: Journal of Taphonomy, v. 6, no. 1, p. 21-40.

Cohen, Y., 1989, Preface, in Cohen, Y., and Rosenberg, E., eds., Microbial Mats: Physiological Ecology and Benthic Microbial Communities: American Society for Microbiology, Washington, p. xv-xvii.

Decho, A.W., and Kawaguchi, T., 2003, Extracellular polymers (EPS) and calcification within modern marine stromatolites: Annual Review Earth Science, v. 31, p. 227-239.

Dunn, K.A., Mclean, R.J.C., Upchurch, G.R., and Folk, R.L., 1997, Enhancement of leaf fossilization potential by bacterial biofilms: Geology, v. 25, no. 12, p. 1119-1122.

Dupraz, C., and Visscher, P.T., 2005, Microbial lithification in marine stromatolites and hypersaline mats: Trends in Microbiology, v. 13, no. 9, p. 429-438.

Dupraz, C., Reid, R.P., Braissant, O., Decho, A.W., Norman, R.S., and Visscher, P.T., 2009, Processes of carbonate precipitation in modern microbial mats: EarthScience Review, v. 96, no. 3, p. 141-162. 
Esperante, R., Brand, L., Nick, K.E., Poma, O., and Urbina, M., 2008, Exceptional occurrence of fossil baleen in shallow marine sediments of the Neogene Pisco Formation, Southern Peru: Palaeogeography, Palaeoclimatology, Palaeoecology, v. 257 , no. 3 , p. $344-360$.

Fregenal-Martínez, M.A., and Buscalioni, A.D., 2009, Las Hoyas Konservat Lagersttäte: A field-trip to a Barremian subtropical continental (wetland) ecosystem: Fundamental, Fundación Conjunto Paleontológico de Teruel, v. 14, p. 131-152.

Gall, J.C., 1990, Les Voies Microbiens. Leur contribution à la fossilization des organismes au corps mou: Lethaia, v. 23, p. 21-28.

Gall, J.C., Bernier, P., Gaillard, C., Barale, G., Bourseau, J.P., Buffetaut, E., and Wenz, S., 1985, Influence du développement d'un voile algaire sur la sédimentation et la taphonomie des calcaires lithographiques. Exemple du gisement de Cerin (Kimmeridgien supérieur, Jura méridional français): Comptes Rendus de l'Académie des Sciences de Paris, v. 301, no. 8, p. 547-552.

Genling, J.G., 1999, Microbial mats in terminal Proterozoic siliciclastics; Ediacaran death masks: PALAIOS, v. 14, no. 1, p. 40-57.

Grimm, J., Potthast, A., Wunder, A., and Moore, A., 2003, Magnetic resonance imaging of the pancreas and pancreatic tumors in a mouse orthotopic model of human cancer: International Journal of Cancer, v. 106, no. 5, p. 806-811.

Guerrero, M.C., Balsa, J., Pascual, M., Martínez, B., and Montes, C., 1991, Caracterización limnológica de la laguna Salada de Chiprana (Zaragoza, España) y sus comunidades de bacterias fototrófica: Limnetica, v. 7, p. 83-96.

Krumbein, W.E., 1979, Calcification by bacteria and algae, in Trudinger, P.E., and Swaine, D.J., eds., Biochemical Cycling of Mineral-Forming Elements: Elsevier Amsterdam, p. 47-68.

Krumbern, W.E., Cohen, Y., and Shilo, M., 1977, Solar Lake (Sinai) 4. Stromatolitic cyanobacterial mats: Limnology and Oceanography, v. 22, p. 635-656.

Kühl, M., Fenchel, T., and KazmierczaK, J., 2003, Growth, structure and calcification potential of an artificial cyanobacterial mat: Annual Review Earth Science, v. 31, p. 77-103.

Ludwig, R., Al-Horani, F.A., De Beer, D., and Jonkers, H.M., 2005, Photosynthesiscontrolled calcification in a hypersaline microbial mat: Limnology and Oceanography, v. 50, no. 6, p. 1836-1843.

Mancuso, A.C., 2003, Continental fish taphonomy: A case study in the Triassic of Argentina: Journal of South American Earth Sciences, v. 16, p. 275-286.

Martill, D.M., Brito, P.M., and Washington-Evans, J., 2008, Mass mortality of fishes in the Santana Formation (Lower Cretaceous, Albian) of northeast Brazil: Cretaceous Research, v. 29, p. 649-658.

Martín-Abad, H., and Poyato-Ariza, F.J., 2010, An actuotaphonomical approach to factors of fish preservation in Konservat-Lagerstätten: In Gonzalez-Rodríguez, K.A., and Arratia, G., eds., Fifth International Meeting on Mesozoic Fishes: Global Diversity and Evolution, Saltillo, Mexico: Universidad Autónoma del Estado de Hidalgo, Pachugo, Mexico, p. 66.

Martínez-Delclós, X., Briggs, D.E.G., and Peñalver, E., 2004, Taphonomy of insects in carbonates and amber: Palaeogeography, Palaeoclimatology, Palaeoecology, v. 203, p. 19-64.

NofFKe, N., 2009, The criteria for biogeneicity of microbially induced sedimentary structures (MISS) in Archean and younger, sandy deposits: Earth Science Reviews, v. 96 , p. $173-180$.
Novelline, R.A., 2004, Squire's Fundamentals of Radiology (6th edition), chapter 2 : Harvard University Press, Cambridge, United States, p. 36-39.

O'Brien, N.R., Meyer, H.W., Reilly, K., Ross, A.M., and Maguire, S., 2002, Microbial taphonomic processes in the fossilization of insects and plants in the late Eocene Florissant Formation, Colorado: Rocky Mountain Geology, v. 37, no. 1, p. 1-11.

O'Brien, N.R., Meyer, H.W., and Harding, I.C., 2008, The role of biofilms in fossil preservation, Florissant Formation, Colorado: Geological Society of America Special Papers, v. 435, p. 19-31.

Peñalver, E., 2001, Los insectos dípteros del Mioceno del Este de la Península Ibérica; Rubielos de Mora, Ribesalbes y Bicorp. Tafonomía y sistemática: Ph.D thesis, Universitat de València, Valencia, $550 \mathrm{p}$.

Raff, E.C., Schollaert, K.L., Nelson, D.E., Donoghue, P.C.J., Thomas, C.W., Turner, F.R., Stein, B.D., Dong, X., Bengtson, S., Huldtgren, T., Stampanoni, M., Chongyu, Y., and Raff, R.A., 2008, Embryo fossilization is a biological process mediated by microbial biofilms: Proceedings of the National Academy of Sciences, v. 105, no. 49, p. 19360-19365.

Riches, S.F., Payne, G.S., Morgan, V.A., Sandhu, S., Fisher, C., Germuska, M., Collins, D.J., Thompson, A., and De Souza, N.M., 2009, MRI in the detection of prostate cancer: Combined apparent diffusion coefficient, metabolite ratio, and vascular parameters: American Journal of Roentgenology, v. 193, no. 6, p. 15831591.

Sagemann, J., Bale, S.J., Briggs, D.E.G., and Parkes, R.J., 1999, Controls on the formation of authigenic minerals in association with decaying organic matter: An experimental approach: Geochimica et Cosmochimica Acta. v. 63, no. 7-8, p. $1083-1095$.

SeIlacher, A., 1990, Taphonomy of Fossil-Lagerstätten, in Briggs, D.E.G., and Crowther, P.R., eds., Palaeobiology: A Synthesis: Blackwell Science Ltd., Oxford, UK, p. 266-270.

SeIlacher, A., 2009, Biomats and preservation in lithographic limestones: In BillonBruyat, J.-P., Marty, D., Costeur, L., Meyer, C.A., \& Thüring, B., eds., 5th International Symposium on Lithographic Limestone and Platenkalk: Société jurassienne d'émulation, Basel, Switzerland, p. 41.

Seilacher, A., Reif, W.E., and Westphal, F., 1985, Sedimentological, ecological and temporal patterns of fossil Lagerstätten: Philosophical Transactions of The Royal Society of London, v. 311, p. 5-23.

VioHL, G., 1994, Fish taphonomy of the Solnhofenplattenkalk: An approach to the reconstruction of the palaeoenvironment: Geobios, v. 27, no. 1, p. 81-90.

Wierzchos, J., Berlanga, M., Ascaso, C., and Guerrero, R., 1996, Micromorphological characterization and lithification of microbial mats from the Ebro Delta (Spain): International Microbiology, v. 9, p. 289-295.

Wilby, P.R., Briggs, D.E.G., Bernier, P., and Gaillard, C., 1996, Role of microbial mats in the fossilization of soft tissues: Geology, v. 24, no. 9, p. 787-790.

Wilson, M.V.H., 1988, Reconstruction of ancient lake environments using both autochthonous and allochthonous fossils: Palaeogeography, Palaeoclimatology, Palaeoecology, v. 62, no. 1-4, p. 609-623.

ACCEPTED NOVEMBER 30, 2012 